\title{
Hosting an international librarian
}

\author{
By Nicoletta Mattioli Hary and Francesca L. Hary
}

\section{This wortbwhile experience requires time and effort}

$\mathbf{F}$ or almost a century American librarians have felt the need to share their advanced methods with foreign colleagues. This generosity has allowed many international librarians to be trained in this country and to return home with knowledge acquired in American libraries or library schools. In 1993 the Library Fellows Program, funded by the United States Information Agency (USIA) and administered by ALA, began placing international librarians in U.S. libraries to enhance their professional experience and enable them to gain expertise in a specific area of librarianship.

The Library Fellows Program carefully attempts to match libraries with librarian interests. ALA provides round-trip travel for the fellow and one dependent, a stipend $(\$ 33,000$ per year, prorated for grant duration), basic health insurance, limited funds for authorized travel and purchase of professional materials, a housing subsidy, and an orientation program for fellows and mentors. ALA assists with visa, Social Security, and tax preparation.

This new program supports the teaching mission of librarianship and has stimulated numerous American libraries to host an international librarian. Although prestigious for the host library and rewarding for staff involved, this type of hospitality requires extraordinary commitment from the host library.

The rewards may outweigh the efforts involved, but hosting an international librarian is quite different from training an American li- brary intern. More time is required on the job and there are more responsibilities outside the workplace. The host library must plan on donating considerable staff time and some modest amount of money.

Before inviting an international librarian, a library's administration must consider not only if it can accommodate the interests of the guest or whether a staff librarian with appropriate expertise is willing to act as mentor, but also staff time, institutional enthusiasm for the project, housing availability, and budget.

This article (suggested by a recent hosting experience) aims to clarify what a host library and its staff should be ready to offer an international fellow.

\section{Begin with training}

Providing suitable training for the guest is paramount. Since interaction is vital during training, it is important that the visiting librarian be in or near the work area of the mentor. A work space similar to those of other professionals should be prepared (equipped with a personal computer from which the library's online catalog, CD-ROM databases, and the Internet can be accessed).

Upon arrival, the visiting librarian should be introduced by the mentor to library administrators and the staff of the department where he/she will be working. After that, the guest should receive a general tour of the library, to be followed in time by more in-depth visits to each area. Training activities in other areas of the library should be coordinated by the mentor with the respective supervisors; the fellow should "job-shadow" professionals in these different areas. This broader experience will help 
the guest librarian understand the current development of librarianship in the United States. Such training activities could be brief or more intense, depending on the interest of the guest.

There should be a training plan in place from the beginning. The mentor should meet with the fellow to discuss goals and objectives and their attainment. Goals might well change once the fellow realizes all available opportunities. The mentor should encourage the trainee to take advantage of learning opportunities at the host institution.

It is of utmost importance that the international librarian receive all the training needed in the specific area of librarianship selected for emphasis. Thus, it is imperative that the mentor have extensive experience in that area. Training requires attention as well as supervision; both are best given if teacher and student work closely together. While it is important that the guest librarian do some meaningful work, the focus should remain on training rather than on any contribution to the hosting department.

In adclition to being informed of training opportunities and conditions, the fellow should also be told about attendance expectations and the privileges extended by the host library. It is best to agree on these matters from the start of the relationship. The guest should be trusted like any staff member; he/she should be given keys and passwords. Along with providing the visitor with a borrower's card, it seems appropriate to offer free photocopying.

\section{Involving the community}

Shortly after the fellow's arrival, the hosting institution should arrange for publicity; interviews with the local newspaper, the library's newsletter, and/or campus publications can focus on the goals and learning expectations of the visitor, conditions of libraries in the guest's country, or comparisons of student life there with that of the U.S. Informing the local community and the library's constituents of the presence of the fellow will benefit both the guest and the hosting institution.

The international librarian should be given opportunities to visit different types of libraries in the region; it would seem valuable to see at least one academic library, a large public library, the branch of a public library, a corporate library, and a school library. Any expenses incurred with making such visits should be underwritten by the host library. Naturally, the guest should be included in all pertinent staff meetings, socials, or cultural events sponsored by the library. During the visit, the fellow might like to share his/her culture with the library staff or a larger audience. If this is the case, the mentor should make the arrangements.

Since establishing useful professional contacts is one purpose of the Library Fellows Program, host library staff should assist the guest in making such connections. It might be useful for the visitor to talk with the OCLC representative and American book vendors serving the area of his/her country. Whenever possible, the international librarian should attend (subsidized by the host library) local and regional library conferences. The program funds the fellow's attendance at one national conference, but smaller conferences will also contribute to a better understanding of the professional activities of American librarians.

\section{Housing and accommodations}

The host library is responsible for securing suitable housing for its guest. Since the fellow is allowed to bring a dependent, lodging with others in a private home is not always suitable. The best accommodation is probably a small apartment located near the library or convenient to public transportation. If the host library is part of an academic institution, it might be possible to secure campus housing. Proximity to the library is advisable; it reduces commuting time and allows the visitor to return to the library at any time.

Securing beforehand a private furnished apartment could be a more difficult task, but it is a good iclea to have housing ready when the guest arrives. If this is not done, temporary accommodations will have to be secured, either in a hotel or in someone's home. Furthermore, private apartments and campus housing normally contain only essential furniture. Such necessary items as linens, dishes, cooking utensils, lamps, radio, and television are usually lacking. It would be a welcoming gesture if the library staff offered to provide these items along with some basic food supplies. Once housing is secured, the library should promptly inform the fellow of the details of the situation.

Since the fellow may not elect to have a telephone in the apartment due to expense, the library should be ready to offer assistance, not only for local calls but also for some limited long distance calling. Allowing the guest to make one brief weekly phone call home at 
the library's expense seems a reasonable and affordable courtesy.

\section{Acculfuration concerns}

Coming from another country and culture, the guest librarian will need help becoming familiar with the American way of life. Offering a television for the apartment is important because it will increase exposure to American culture, keep the fellow informed of the news, and provide exercise in understanding spoken American English. Since social etiquette varies among countries, guests may need some occasional advise on how to meet situations that are new to them. Help will be most needed with practical everyday matters, such as where to shop economically or how to rent a car.

The guest should have opportunities to learn as much as possible about the U.S. This can be done in various ways: inviting the fellow to one's home; visiting local museums and historical sites; attending lectures, concerts, shows, and movies; and traveling on weekends to visit other cities or neighboring states. Attendance at an American graduation ceremony should be encouraged since it is an event most foreign countries don't have.

Most of these activities must be suggested by the mentor or other American colleagues willing to spare the time and do the driving. If this willingness is lacking, the fellow could spend weekend after weekend confined to his/ her apartment. The staff of the host library must recognize that the responsibility of providing hospitality for such a guest is not limited to the scheduled work week.

\section{Responsibility of the mentor}

Selecting the right person to be the mentor is critical to the success of the hosting experience since the mentor will be the active channel through which the entire experience will be funneled. In assuming this role, however, he/she should be ready to carry it out almost single-handedly. Colleagues will give some assistance with training and entertainment, but it will be the mentor's task to organize and coordinate these activities. Experience has shown that the fellow will depend primarily on the mentor for all his/her professional and personal needs. For instance, the mentor may have to make sure the visitor has transportation to the supermarket and the laundromat at least once a week. At work, mentoring will take time away from regular duties and, depending on circum- stances, the mentor might have to make up some of this time. Since mentoring may also entail some extra expenses-such as transportation costs or occasional meals-the library should be willing to provide the mentor with just reimbursement.

\section{Conclusion of the experience}

Before departing, the fellow should have a debriefing session with the mentor. $\mathrm{He} /$ she should also meet with the supervisor of the hosting department and the library director. These exit interviews will allow the fellow and his/her hosts to handle unresolved issues and discuss the positives and negatives of the experience. Hopefully, both parties will have a sense of accomplishment. Undoubtedly, both will have contributed to better international understanding. To the staff of the hosting institution, the results will prove their efforts were worthwhile; the international fellow will return home with sharper skills and a wealth of new and useful knowledge

A farewell party for the departing fellow is also appropriate. Short speeches, the presentation of letters of recognition, and small gifts representative of the hosting institution are fitting. It is also desirable that the hosting librarians remain in touch with their guest in order to continue their professional exchanges as well as their friendships.

\section{Benefits worth the effort}

The rewards of hosting a foreign librarian far outweigh any necessary work or expense. Participation in the USIA/ALA Library Fellows Program brings recognition to a library and its staff. Certainly the personal credentials of the mentor will be enhanced by the experience. The entire library staff will also benefit from the presence of a visiting foreign librarian who will bring unique abilities and experience to the job. Beyond the institutional and personal benefits, the hosting library and its staff will have fulfilled their greater obligation towards the profession, the international library community, and the world.

If you or your library are interested in hosting a non-U.S. librarian, contact Robert Doyle, Director, Library Fellows Program, American Library Association, 50 East Huron St., Chicago, IL 60611 ; phone: (312) $280-3200$ or ( 800 ) 545 2433, ext. 3200; Telex 4909992000 ALA UI; fax: (312) 944-3897; e-mail: ROBERT.P.DOYLE @ALA.ORG. 


\section{The Statesman's Year-Book 1994-95 \\ |3|st edition Edited by Brian Hunter}

'The Statesman's Year-Book contains all you need to know about the population of various states and countries, officials, exports, constitutions, governments, diplomatic representatives, religion, finance and basic histories."

$$
\text { - The New York Times }
$$

"An indispensable reference work."

$$
\text { - The Wall Street Journal }
$$

The latest edition of The Statesman's YearBook includes coverage of recent developments in the European Union, Bosnia, Israel, Russia and South Africa.

ISBN 0-312-12194-6 \$89.95 $\quad$ 1,700 pp. with map

\section{Who's Who 1995}

\section{An Annual Biographical Dictionary, 147th Edition}

"The pioneer of all works using the title Who's Who. This accurate compilation covers persons of distinction in all fields of endeavor."

-ALA Reference and Subscription Books Review Committee

Who's Who 1995 is packed with more than 29,000 detailed entries on the backgrounds, life histories, and interests of thousands of distinguished personalities.
ISBN 0-312-12413-9
$\$ 195,00 \quad 2,300 \mathrm{pp}$.

\section{The Encyclopedia of Science Fiction}

\section{John Clute and Peter Nicholls}

"Those lucky enough to own a copy of the first edition from 1979 have surely smudged and dog-eared the volume from over a dozen years of poring over what was the most important SF reference book ever produced. This new volume with a $56 \%$ increased word count to $1,300,000$ words, is a must for the book shelf of any SF devotee."

ISBN 0-312-09618-6 - Science Fiction Age $\$ 75.00 \quad 1.408 \mathrm{pp}$.

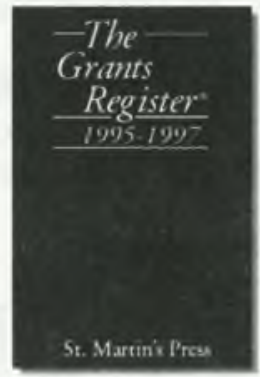

\section{The Grant's Register 1995-1997}

\section{Thirteenth Edition Edited by Lisa Williams}

"One of the first books that a library should have." -Books West

The Grant's Register 1995-1997 is extensively revised and updated with information on over 2,000 sources of funds covering all disciplines. The book includes over 6,000 awards and grants, and it lists awards from regional, national, and international sources tenable in the U.S., Canada, and abroad.

ISBN 0-312-10387.5 $\$ 95.00 \quad 832 \mathrm{pp}$.

\section{Dictionary of Contemporary American Artists}

\section{Sixth Edition Edited by Paul Cummings}

"For those of you who want just the facts and not the fluff .. make Dictionary of Contemporary American Artists your reference of choice."

-Antique Week

This invaluable guide is the only reference of its kind. Paul Cummings has compiled information on more than 900 contemporary painters, sculptors, and printmakers. Illustrated, information-packed, and completely up-to-date, this dictionary is an important resource for all libraries.

ISBN 0-312-08440-4 $\$ 85.00 \quad 800$ pp.illustrated

\section{$\checkmark$ THE BEST IN REFERENCE}

\section{St. Martin's Press}

Scholarly \& Reference Division - 257 Park Avenue South NY, NY • 1-800-221-7945 


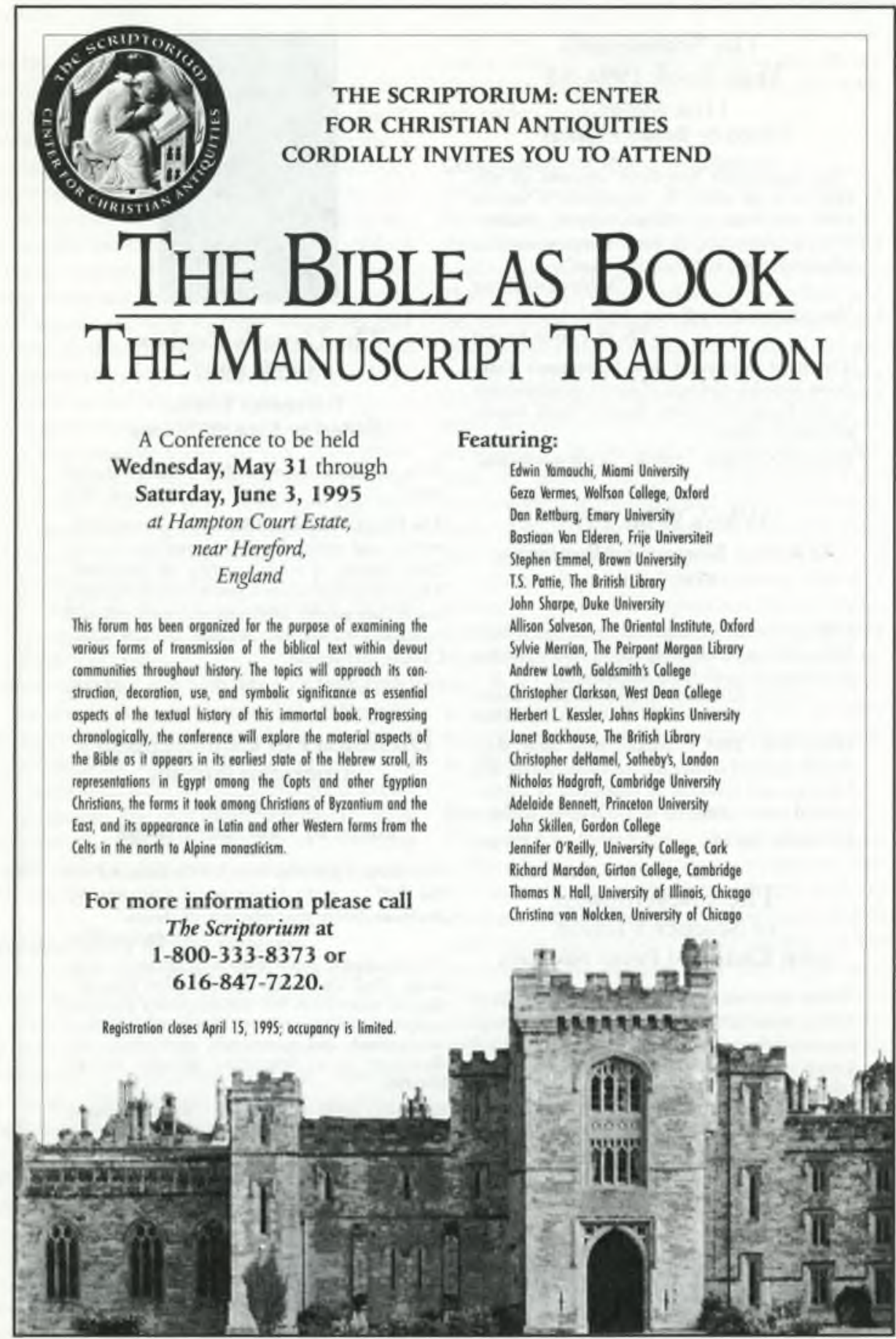

